\title{
Transient Stability Analysis of Large-Scale PV Penetration on Power Systems
}

\author{
Mohammed A. Almutiari \\ Center of Research Excellence in Renewable Energy \\ and Power Systems \\ Department of Electrical and Computer Engineering \\ Faculty of Engineering \\ K. A. CARE Energy Research and Innovation \\ Center \\ King Abdulaziz University \\ Jeddah 21589, Saudi Arabia
}

\author{
Muhyaddin J. Rawa \\ Center of Research Excellence in Renewable Energy \\ and Power Systems \\ Department of Electrical and Computer Engineering \\ Faculty of Engineering \\ K. A. CARE Energy Research and Innovation \\ Center \\ King Abdulaziz University \\ Jeddah 21589, Saudi Arabia
}

\begin{abstract}
With the continuous expansion and upgrading of power networks, most countries tend to exploit the renewable energy sources available to them to facing the increasing of system load or to compensate the power shortage in the system or to replace the conventional generator (SG) by large scale photovoltaic (LSP) plant. This paper deals with a representation of a real network using the powerfactory DIgSILENT program to examine the transient stability analysis of power grid under three cases, increasing of the system load, compensation of the power shortage from the generator with LSP plant and replacement of the SG by the LSP plant. The different level of the LSP penetration are considered in some assumed cases to examine the variation of the rotor angle and bus voltage after a three phase fault. The results of the transient stability analysis have been plotted and presented.
\end{abstract}

Keywords - Large- Scale Photovoltaic (LSP), Transient Stability, Power System, DIgSILENT, Rotor Angle.

\section{INTRODUCTION}

Almost of the world countries now has a challenge regarding to the providing and producing the energy and electric power from sustainable or renewable energy instead of using conventional power plants that depending on fossil fuels like oil, coal and natural gas. The fossil fuels are limitations resources which in any time could be run out, however, the huge impacts on environments which caused pollutions, carbon dioxide emission, global warming. Many governments promote and boost using renewable energy to meet the future electricity demand. By the end of 2018, global renewable generation capacity increased by $171 \mathrm{GW}$ and reached 2,351 GW worldwide. This represents a yearly growth of around $7.9 \%$, the average for seven straight years in a row, according to new data released by the International Renewable Energy Agency (IRENA) [1]. The renewable energy continues to move forward at a fast pace due to falling price and improved the used technology and their performance. Solar photovoltaic (PV) array is the most growing technology between the other renewable energy resources, with a capacity increase of $94 \mathrm{GW}$ [2]. Asia continued to dominate global growth with a $64 \mathrm{GW}$ increase (about 70\% of the global expansion in 2018). Maintaining the trend from last year, China, India, Japan and Republic of Korea accounted for most of this [3]. In Saudi Arabia, the power generation still depend on fossil fuels where consume around 3 million barrels/day [4]. Currently, Saudi Arabia plans to produce 9.5 gigawatts from renewable energy by 2023 as a part of the Kingdom's 2030 vision [5]. Solar PV system has many advantages among other renewable energy, where no moving mechanical parts, noiseless, compact size and less maintenance. Due to rapidly growth of renewable power energy sources and penetrated with conventional generation and grid to cover the rising demand on the energy and the desire of governments and organizations to reduce the overall cost and increase the efficiency, there is an urgent need to study and analyze the impact of such renewable energy sources penetration in existing power networks and development of control systems to support and increase the stability of energy systems.

Many researches and studies were conducting on solar photovoltaic (PV) array regarding to the steady state and transient stability aspects of grid connected systems. Some papers demonstrated the beneficial and detrimental impacts of high penetration of PV system into the grid. Another research presented the different technologies of inverter with various capabilities and their effect on the grid stability. Also, some study investigated the impact of grid fault on the operation performance of PV system. In [6] The study shows the impact of increased penetration of PV systems on static performance and transient stability in the transmission level, the simulation results revealed that increasing PV penetration levels can lead to alteration of the steady state voltage magnitudes and overvoltages at the buses. However, in transient studying the results show detrimental and beneficial impact on the system according to the system topology, type and location of the fault. In [7], This paper investigates the impact of increased penetration of large-scale photovoltaic LSP generation on the short-term stability of power system. The results show that the greater instability conditions are reported if Full Replacing 
International Journal of Engineering Research and Technology. ISSN 0974-3154, Volume 13, Number 5 (2020), pp. 1030-1038

(C) International Research Publication House. https://dx.doi.org/10.37624/IJERT/13.5.2020.1030-1038

(FR) of Conventional Generating Units (CGU) is considered. However, fewer instability conditions are obtained if Partial Replacing is considered instead of FR since CGU keep excitation control systems (AVR, exciter) and turbine governor controls activated. Also, the results are demonstrated that utilizing LSPVSs with Q regulation capabilities are more beneficial rather than employing LSPV systems with no Q regulation. In [8], This study analyzed the impact of large-scale photovoltaic connected into the grid on dynamic voltage stability. Its concluded that the LSP plant can improve system stability, reduce angle and voltage instability, and enhance the reliability of the whole power system. In [9], This paper investigated the impact of large penetration of solar PV systems on steady state performance and transient stability without any specialized controls just the controls existing in a conventional power plant to manage grid stability. The study proved that the steady state voltages are affected adversely with the location and the level of PV penetration. Also, the bus voltage magnitudes and relative rotor angle are adversely affected during the transient's performance with high penetration of PV. In [10], This paper investigated the effect of the different capacity of PV system connected on the system and their Under-Voltage Ride Through (UVRT) characteristics on the system transient stability. The results of the study indicate that an up to certain capacity of PV penetration on the system enhance the power system transient stability. In [11], it has shown that the maximum renewable energy (RE) generation like PV plant can be doubled without violation of voltage profile by introducing voltage and reactive power control capabilities. Also, in dynamic voltage stability analysis, the injected reactive currents by PV plant have contributed in supporting the voltage levels at the generation buses during fault condition. Author in [12] the large PV plant should remain connected to the power grid during large disturbance where the outage of PV plant may have negative impact on the voltage recovering. In [13], the impact of the solar energy on the grid performance (based on the actual grid pattern) was studied and examined under fault occurrence. The results show that the high level in PV penetration contribute to keeping voltage stable when fault occurs outside PV plant. In [14], the transient stability analysis is performed on an IEEE 5-bus system with and without PV penetration to check the behavior of the system under fault conditions. The result show that the system is failed to retain its stability at higher level penetration of PV.

In this paper, the impact of the penetration of LSP plant on the power system transient stability is discussed based on the real data using numerical simulation DIgSILENT software tool (DIgSILENT, 2019) [15]. The transient stability analysis is examined under three cases, increasing of system load, compensate of power shortage by LSP system and replacement of one SG with LSP. The dynamic model of the generators with exciter, governor and PSS and LSP system with LVRT capability are used in this test. In the first two cases, the variation of rotor angle and bus voltage after three phase fault have been studied. Also, the generator speed, bus voltage, active and reactive power were discussed. The results have been plotted and presented.

\section{TRANSIENT StabiLITY ANALYSIS}

Power system stability can be defined as the ability of a system to maintain and regain an operating condition after being subjected to disturbance [16]. In general, the stability issues could be divided into three main groups. One group studying the power system under steady state stability, which refers to the capability of power system to remain in synchronism state after exposed to the small and gradual changes of disturbances. The second group, dynamic stability which study of power system under small, continuous and long duration disturbances. The last group is the transient stability analysis (TSA), which examine the power system under large and unexpected disturbances [17]. Transient stability analysis, the main focus in this research, include sever disturbances such as loss of generation, line outages and single line to ground fault. TSA are usually performed during planning stage to determine critical clearing time of circuit breakers, relaying system and voltage level of any part of the system.

The most two factors affecting transient stability of generating unit are critical clearing time and the angular swing. The moment of inertia $(\mathrm{H})$ and the transient reactance $\left(X_{d}^{\prime}\right)$ are strongly affect on both factors. If the transient reactance $\left(X^{\prime}{ }_{d}\right)$ of a system increased the moment of inertia $\mathrm{H}$ will decrease and vice versa. The expanding of power system size resulting to continually decreasing of $\mathrm{H}$ constant, increasing of $\left(X_{d}^{\prime}\right)$ and decreasing the CCT. As a result, the system stability will negatively impact.

The conventional generation, rotating synchronous generators, has a rotational inertia which is substantial requirement for the stable operation of power system. The rotational inertia minimizes the frequency deviations, and thus increases the available response time to react to fault events such as line losses or generation outages [18]. The PV system does not have any moving parts, so it has zero inertia. The increased penetration of PV system into grid lead to reduce the overall inertia in that system, which finally may have negatively affected on system transient stability especially when large scale PV disconnected from network during sever fault.

The electromechanical dynamics behavior can be governing by so called swing equation. This equation describes the output power from the generators which is a nonlinear function of the rotor angle. At steady state condition, the mechanical torque $\left(T_{\text {in }}\right)$ equal the electrical torque $\left(T_{\text {out }}\right)$, which representing a balancing power state, and accelerating torque $\left(T_{a}\right)$ is the difference between $T_{\text {in }}$ and $T_{\text {out }}$. If $\left(\theta_{m}\right)$ represent the angular displacement of the rotor, $(\mathrm{J})$ indicate the total moment of inertia and $t$ refers to time in second. Then, 
International Journal of Engineering Research and Technology. ISSN 0974-3154, Volume 13, Number 5 (2020), pp. 1030-1038

(C) International Research Publication House. https://dx.doi.org/10.37624/IJERT/13.5.2020.1030-1038

the rotor motion of synchronous machine could be described by equation that based on basic principle in dynamics state:

$$
J \frac{d^{2} \theta_{m}}{d t^{2}}=T_{a}
$$

Where $T_{a}=T_{\text {in }}-T_{\text {out }}$

if $\delta_{m}$ refers to rotor position before disturbance, the rotor acceleration then

$$
\frac{d^{2} \theta_{m}}{d t^{2}}=\frac{d^{2} \delta_{m}}{d t^{2}}
$$

Substituting (3.2) into (3.1)

$$
J \frac{d^{2} \delta_{m}}{d t^{2}}=T_{\text {in }}-T_{\text {out }}
$$

We know that the power equals torque times angular velocity $(\omega)$, by multiplying (3) by $(\omega)$, we get

$$
\text { J. } \omega \frac{d^{2} \delta_{m}}{d t^{2}}=P_{\text {in }}-P_{\text {out }}
$$

Where $P_{\text {in }}$ and $P_{\text {out }}$ refers to input mechanical power and output electrical power respectively.

If $M=J . \omega$, which denoted to inertia constant.

The swing equation in terms of the inertia constant will be

$$
M \frac{d^{2} \delta_{m}}{d t^{2}}=P_{\text {in }}-P_{\text {out }}
$$

The relationship between electric angle $(\delta)$ and mechanical angle $\left(\delta_{m}\right)$ is:

$$
\delta=\frac{p}{2} \delta_{m}
$$

The swing equation in terms of the electric power angle

$$
\frac{2}{p} M \frac{d^{2} \delta}{d t^{2}}=P_{\text {in }}-P_{\text {out }}
$$

The swing equation in terms of per unit

$$
\frac{2 H}{\omega_{s}} \frac{d^{2} \delta}{d t^{2}}=P_{\text {in }}-P_{\text {out }}
$$

Where $\mathrm{H}$ is per unit inertia constant, $\omega_{s}$ is the synchronous speed.

\section{Simulation Model}

\section{A. Power System Model}

The local network was used as case study, its composed of 32 busbar, 20 transmission lines, 18 two winding transformer, 8 three winding transformer, 2 generating unit (SG1 and SG2), 26 loads and 10 shunt filter. The system aggregated demand is approximately $325 \mathrm{MW}$ placed on the different load busbars in the network. SG1 is equipped with (EXPIC1) exciter, (IEEEG1) Governor and (PSS2A) power system stabilizer. SG2 is equipped with (SCRX) exciter and (GAST) turbine governor. The network under study consists of different voltage levels, namely $380-132-33-13.8 \mathrm{kV}$. The system is modelled in DIgSILENT powerfactory. The single line diagram of the power system under study is shown in Figure 1.

\section{B. LSP Plant Model}

The PV technology works to convert the direct radiation from the sun into electricity. The grid connected PV systems

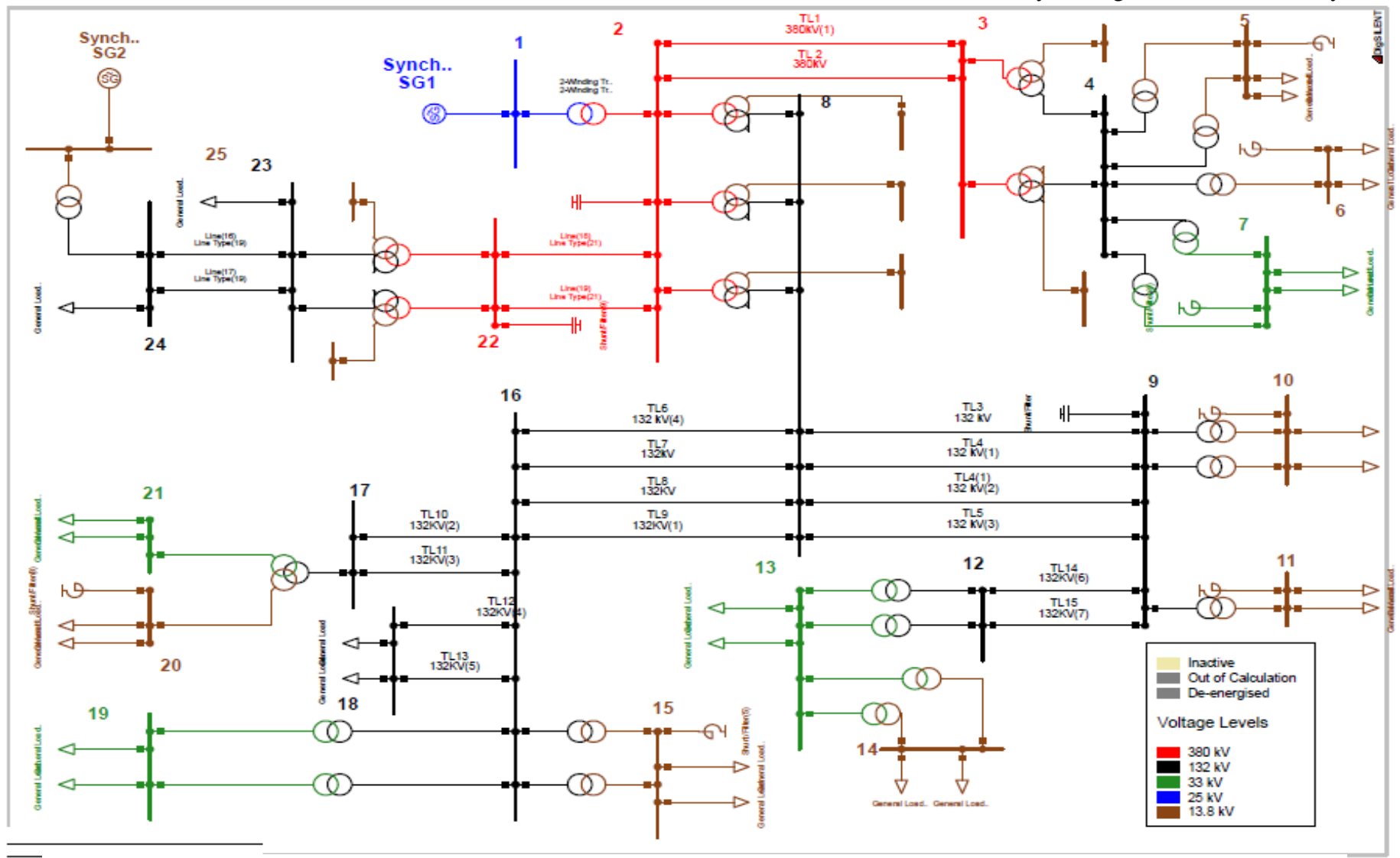

Figure 1 Single line diagram of test network 
International Journal of Engineering Research and Technology. ISSN 0974-3154, Volume 13, Number 5 (2020), pp. 1030-1038

(C) International Research Publication House. https://dx.doi.org/10.37624/IJERT/13.5.2020.1030-1038

components are consists of two units, power conversion unit and interfacing unit. The power conversion unit includes solar PV panels, mounting equipment, DC-DC converter and DC cabling. The interfacing unit including DC-AC converter, AC cabling and step up transformer to connect the PV system to the grid as shown in Figure 2.

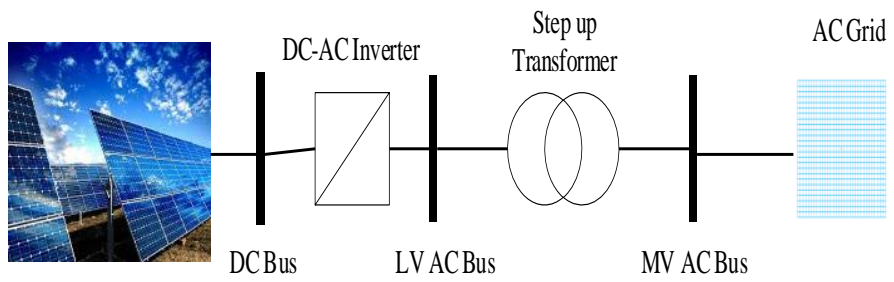

Figure 2 Grid connected PV system components

The solar PV system in the DIgSILENT PowerFactory software is represented by the dynamic solar PV model (500 kVA three-phase solar PV Model) [19]. The solar PV system parameters are given in the appendix. The LSP system is represented by appropriate number of parallel connected 500 $\mathrm{kVA}$ solar PV. The control frame of the PV system in dynamic model is shown in figure 3 . The main blocks in the control frame are designed as four models which are Photovoltaic model, DC busbar and capacitor model, active/reactive power controller (PQ controller) and static generator PV system. the Static Generator block role is to interface LSP plant with the $\mathrm{AC}$ grid via the PV inverter. The solar and temperature are assumed constant during the simulation, since studies for a short time during the fault. A schematic of the PQ controller of the PV model is shown in figure 4.

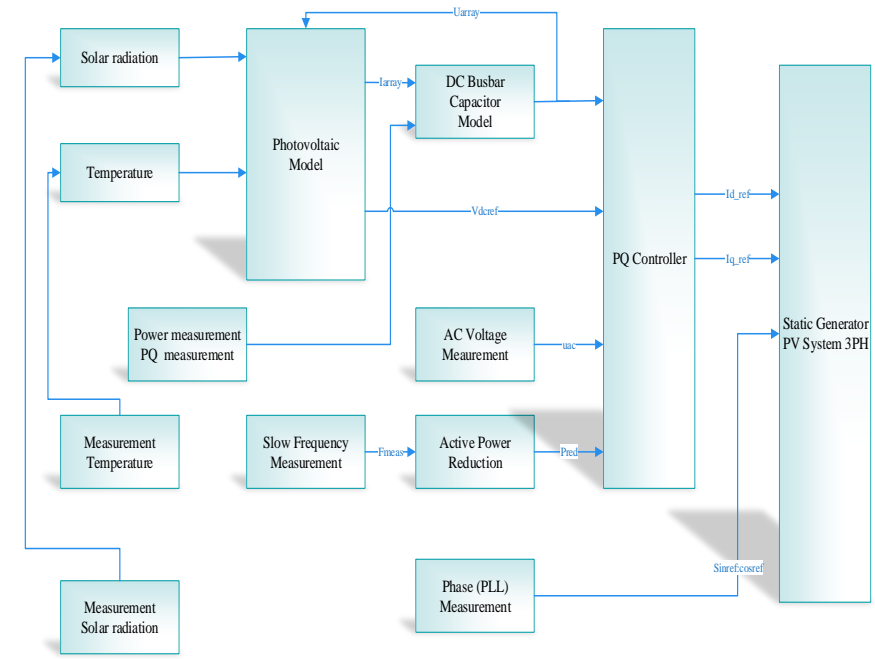

Figure 3 The control frame of solar PV model

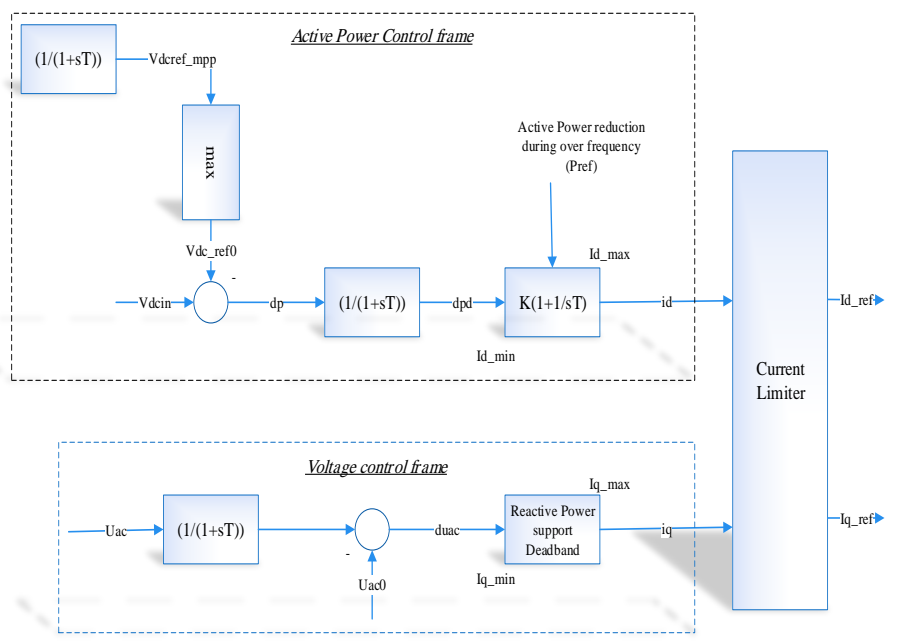

Figure 4 The PQ controller frame of solar PV system

\section{PV Pentration Level}

The PV penetration level is defined as the relative amount of PV solar power injected to the power grid. There are three common classified to describe the contribution of solar power penetration level to the power grid: Instantaneous, Energy and Capacity penetration [6]. The Instantaneous penetration express for the ratio of total PV generated to the total load at a certain time, because of variable natures of PV system and load. The energy penetration is defined as the ratio of the energy that comes from PV system to the load energy over a certain period of a time. Capacity penetration refers to the ratio of the PV capacity to peak load of the system. In this study, the solar PV penetration percentage (SPP) into grid was described as the Eq. (9):

$$
S P P=\frac{P V_{\text {capacity }}}{T L}
$$

Where SPP is solar penetration percentage, $\mathrm{PV}_{\text {capacity }}$ is the total generation capacity from PV plants and TL is the total load of the system.

\section{Grid Codes}

The LSP plants that connected to the power grid, should be comply with grid requirement to work in safe and stable operation. According to many grid code standards. the solar PV plants should support the grid regarding to two points:

- Grid stability.

- During the fault, the PV plant shall remain connected to the network, namely equipped with Low Voltage Ride Through (LVRT).

\section{E. Busbar Voltage Profile}

In this paper, the proposed approach to inject the LSP plant to the network is voltage profiles of busbars. where the Newton Raphson's load flow method was run until the solution was converged with 3 iterations, the result demonstrated that the voltage bus 17 was the lower among the other voltages buses as shown in figure 6 . 
International Journal of Engineering Research and Technology. ISSN 0974-3154, Volume 13, Number 5 (2020), pp. 1030-1038

(C) International Research Publication House. https://dx.doi.org/10.37624/IJERT/13.5.2020.1030-1038

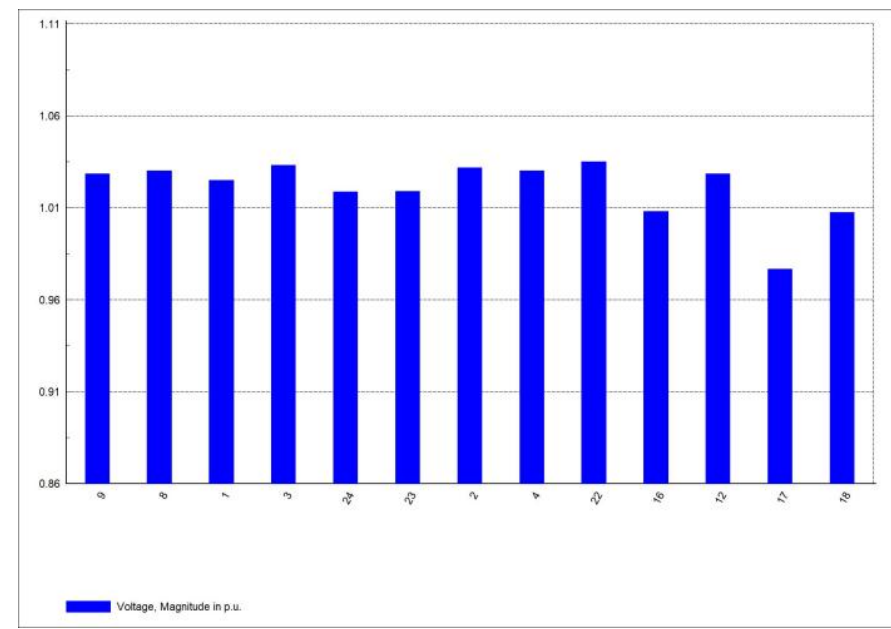

Figure 6 The voltage profile of grid at 380/132 kV levels

\section{RESULTS AND DISCUSSION}

Simulation has been done considering three scenarios for transient stability analysis:

- Scenario 1: The load of the system increases according to the table I. In each case, the transient behavior due to bus voltage has been studied under different level of LSP plant namely 10, 20,30\% penetration in the system.

- Scenario 2: The output power of SG2 reduced gradually and compensate by LSP plant according to the Table II.

- Scenario 3: Replacement of the synchronous generation (SG2) by an aggregated LSP plant to serve the same MW/MVAR demand. The penetration of the LSP in this scenario would create $24.61 \%$.

Table I. THE FIRST SCENARIO

\begin{tabular}{|c|c|c|c|c|}
\hline Case & $\mathbf{1}$ & $\mathbf{2}$ & $\mathbf{3}$ & $\mathbf{4}$ \\
\hline $\begin{array}{c}\text { Increasing of system load } \\
\text { in \% }\end{array}$ & 0 & 10 & 20 & 30 \\
\hline Total Load in MW & 325 & 357 & 390 & 422.5 \\
\hline
\end{tabular}

Table II. THE SECOND SCENARIO

\begin{tabular}{|c|c|c|c|c|c|}
\hline Case & $\mathbf{1}$ & $\mathbf{2}$ & $\mathbf{3}$ & $\mathbf{4}$ & $\mathbf{5}$ \\
\hline SG2 (MW) & 80 & 64 & 48 & 32 & 16 \\
\hline LSP plant (MW) & 0 & 16 & 32 & 48 & 64 \\
\hline $\begin{array}{c}\text { PV based on total output } \\
\text { power of SG2 }\end{array}$ & 0 & 20 & 40 & 60 & 80 \\
\hline
\end{tabular}

\section{A. Scenario 1}

The power network system without solar integration has been considered as the base case with $0 \%$ solar PV penetration. Then LSP plant introduced at bus 17 as mentioned before and its output increased gradually at 10,20 and 30, the result comparing a base case with different penetration of LSP plant, It must be noted that LSP plant system used here is operating at its full active power rating and at voltage control mode.

A bus fault has been considered at bus 8 , as it experiences the maximum short circuit current for its three phase fault. In each case in Table I, a three phase fault has been introduced at bus 8 at " 1 second", the fault was cleared after $300 \mathrm{~ms}$, the relative rotor angle of SG2 and different bus voltage have been monitored and plotted in time domain for " 5 second", in case 1 , where the load is $325 \mathrm{MW}$ is shown in figure 7, cases 2,3 and 4, is shown in figures 8,9 and 10 respectively.

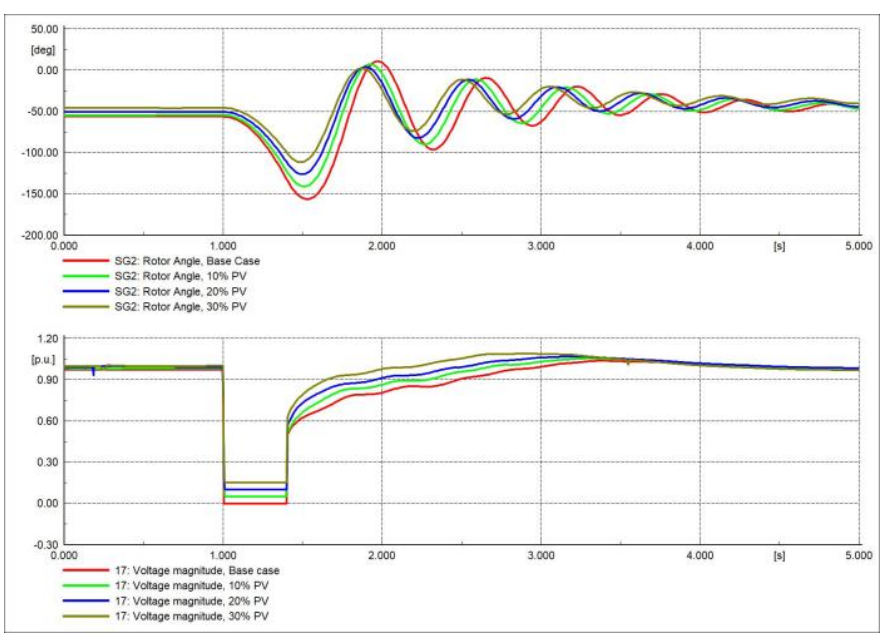

Figure 7 Rotor angle of SG2 and Bus voltage at 17 in Case1.

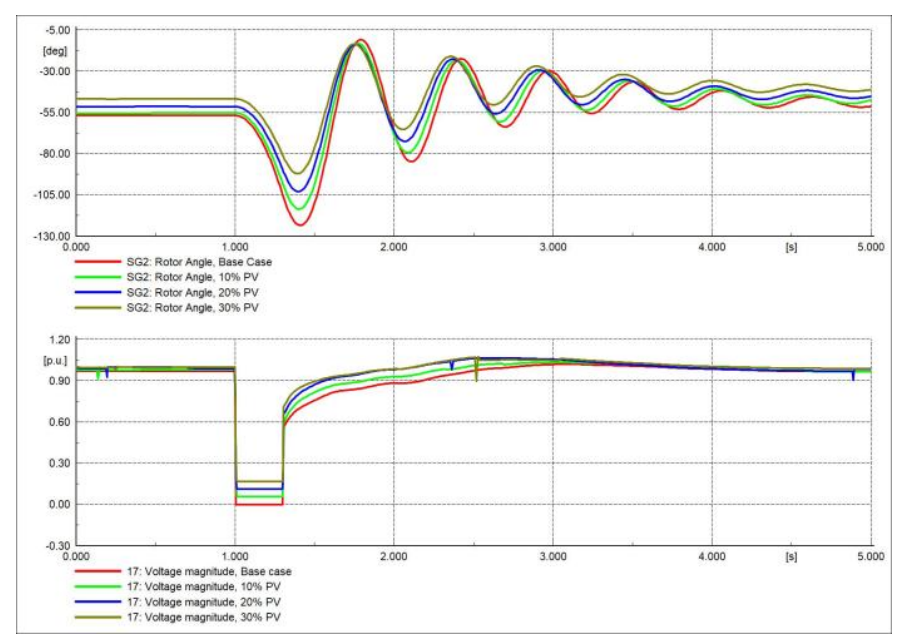

Figure 8 Rotor angle of SG2 and Bus voltage at 17 in Case2. 
International Journal of Engineering Research and Technology. ISSN 0974-3154, Volume 13, Number 5 (2020), pp. 1030-1038

(C) International Research Publication House. https://dx.doi.org/10.37624/IJERT/13.5.2020.1030-1038

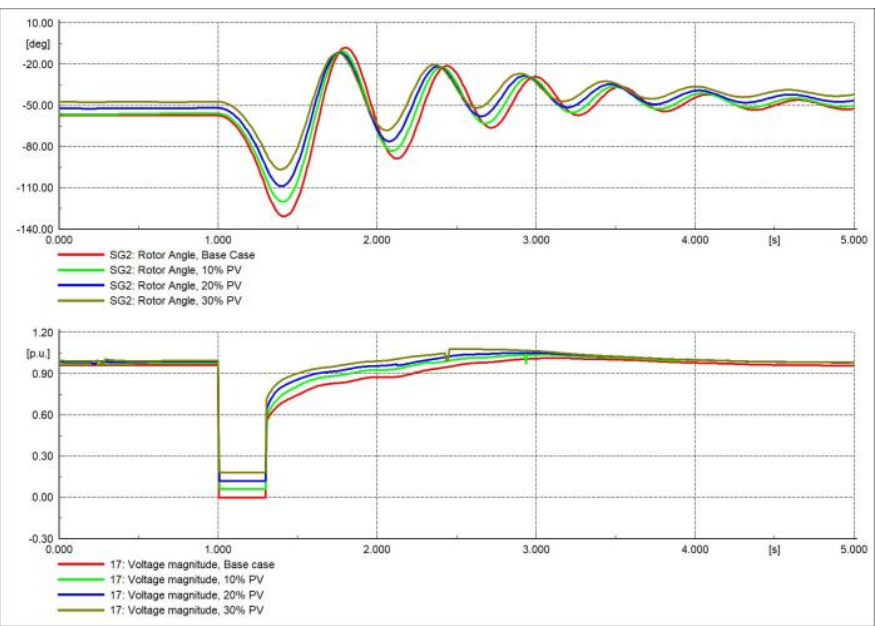

Figure 9 Rotor angle of SG2 and Bus voltage at 17 in Case3.

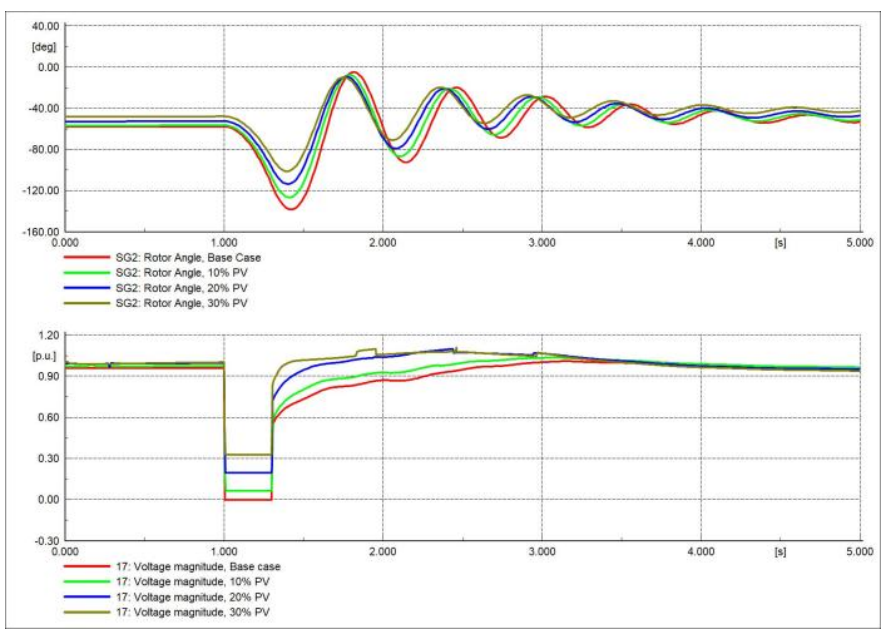

Figure 10 Rotor angle of SG2 and Bus voltage at 17 in Case 4.

It can be noticed that the rotor angle of the generator become less affect during PV penetration and more stable. Also, the bus voltage recovered more speed during PV penetration than the base case where there is no PV. The voltage control scheme in the LSP plant acts fast in comparison to the conventional voltage control scheme of the synchronous generator [21].

\section{B. Scenario 2}

In the second scenario, the transient incident assuming on the 8 busbar occurs at 1 second and clear after $300 \mathrm{~ms}$. The rotor angle plot of SG2, speed plot of SG2 and bus voltages at 24 (where LSP plant connected) and at 8 (where the fault bus occurred) are shown in figures 11,12 , and 13.

The oscillation of the base case is higher than the other cases, when the penetration of PV increased the oscillation of the rotor angle of SG2 decreased until $60 \%$ of penetration PV level, after that the oscillation start increase. When the output power of synchronous generators reduced, the rotational kinetic energy that stored in the power system as a system inertia which play a main role in the system stability reduced also [22].
In the figure 12, it can be seen that the speed of SG2 are more in the base case while the lower speed it can be noted when penetration of PV at $60 \%$ of total output power of SG2. The figure 13 also shows that the response of bus voltage after disturbance was better when PV penetration increased.

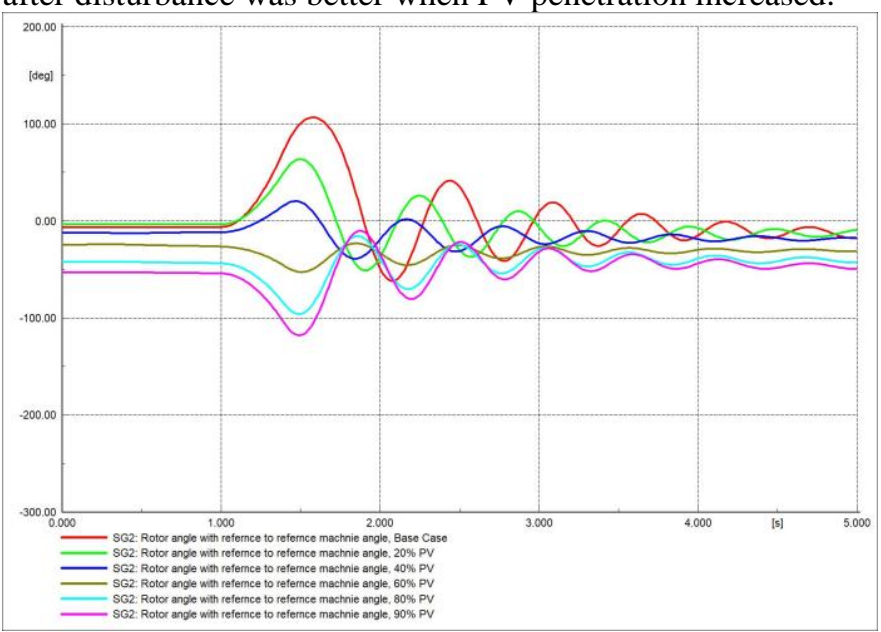

Figure 11 Rotor angle of SG2 in the second scenario.

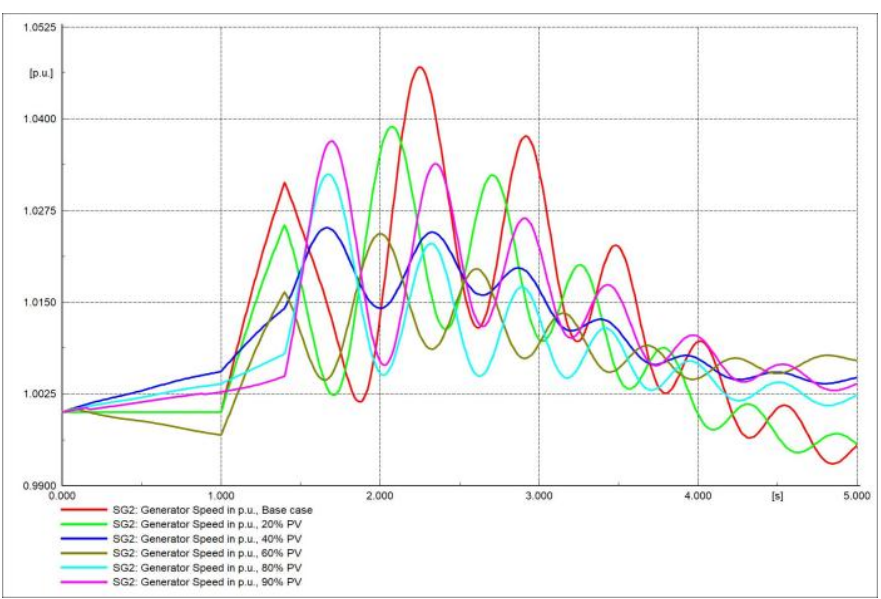

Figure 12 Speed of SG2 in the second scenario.

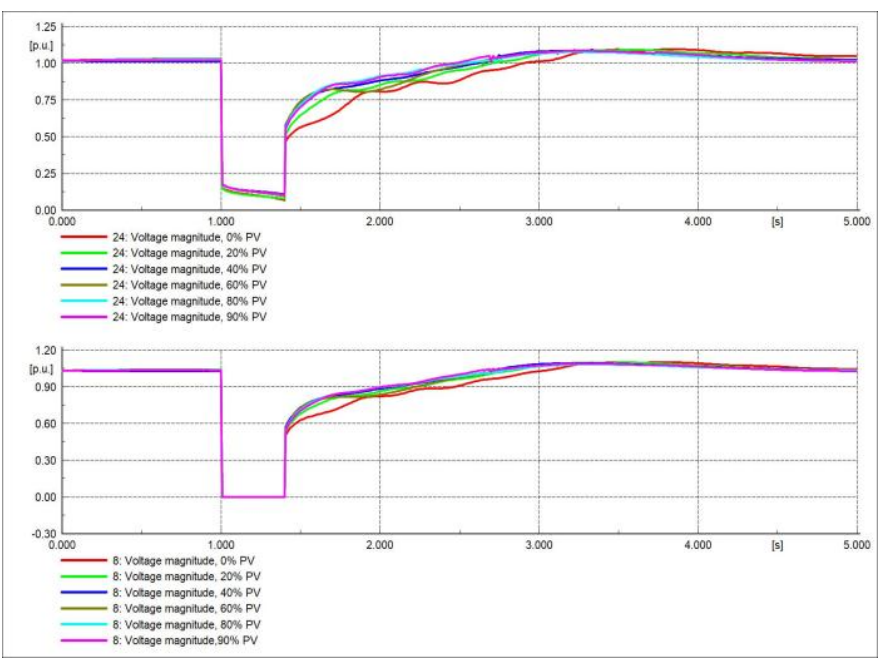

Figure 13 Figure 12 Bus voltages at 24 and 8 buses. 
International Journal of Engineering Research and Technology. ISSN 0974-3154, Volume 13, Number 5 (2020), pp. 1030-1038

(C) International Research Publication House. https://dx.doi.org/10.37624/IJERT/13.5.2020.1030-1038

\section{Scenario 3}

The effect due to loss of transmission line 1 has been studied next. Also, the speed of the generator (SG1), bus voltage magnitude, active and reactive power have been studied. The three-phase short circuit has been introduced at the transmission line 1 at " 1 second" and the circuit breaker opened after $300 \mathrm{~ms}$ as shown in figure 14. The plot of generator (SG1) speed, plot of voltages at bus 2 (from where the transmission line is disconnected), bus 24 (where LSP plant is connected) and bus 8 (away from fault) and plot of active and reactive power of SG1 are shown in figures 15,16 and 17.

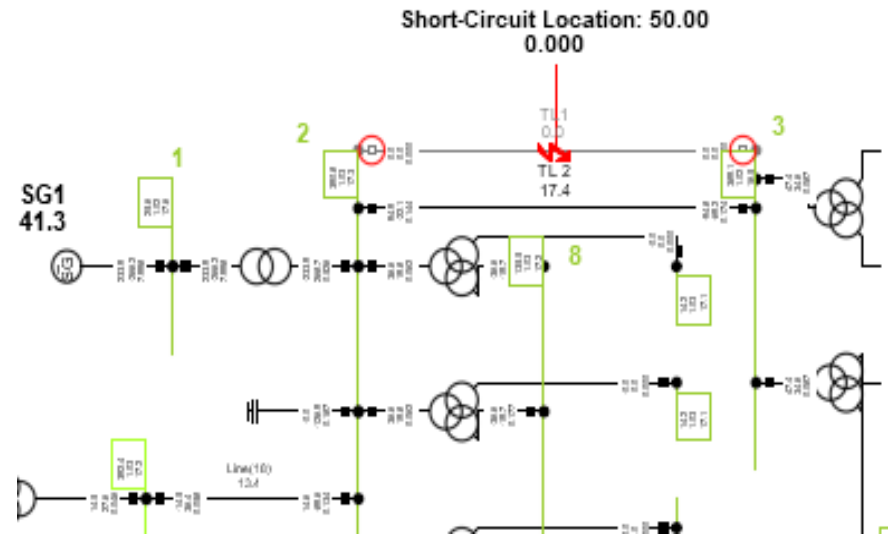

Figure 14 Short Circuit at transmission line 1.

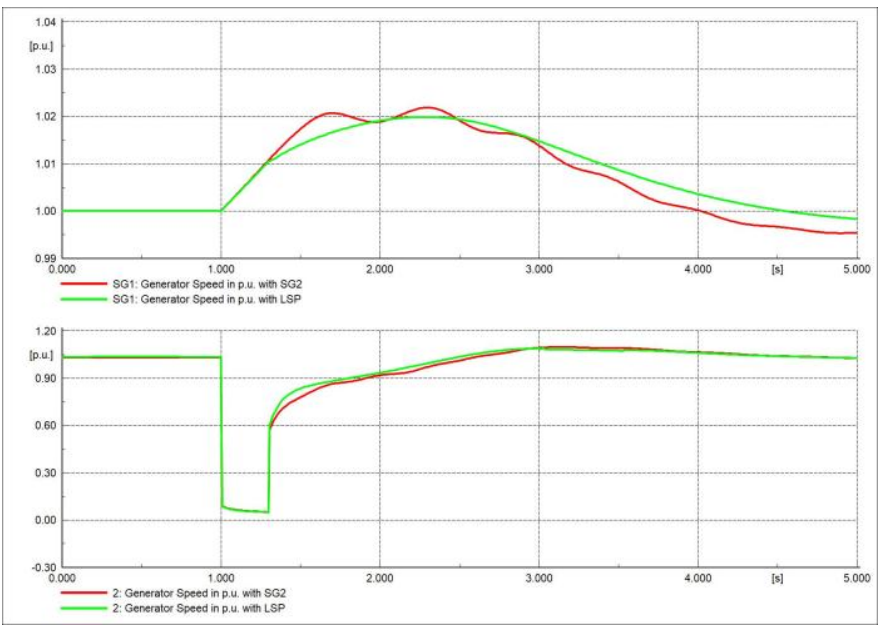

Figure 15 Speed of SG1 and Bus voltage at 2 during loss of transmission line.

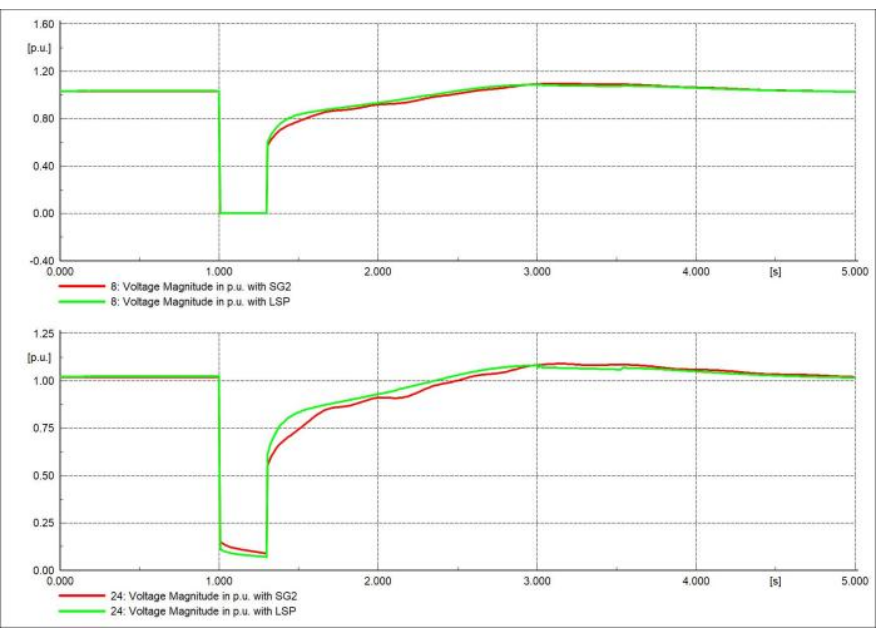

Figure 16 Bus voltages at 8 and 24 during loss of transmission line.

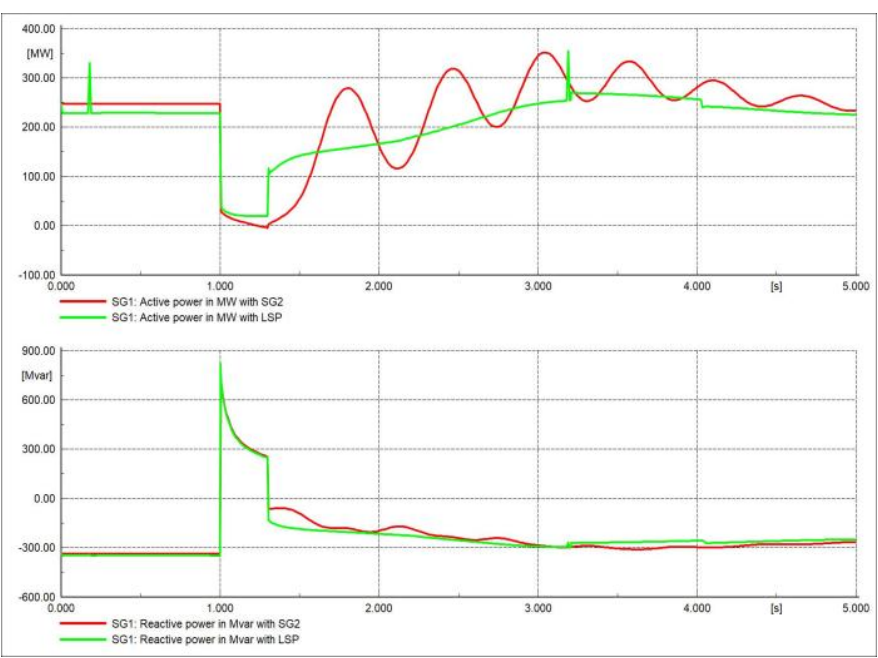

Figure 17 Active and Reactive Power Variation at SG1 for a fault at Bus 8.

As illustrated above, the speed of the synchronous generator SG1 is more with SG2 than with LSP. At the end of the time measured, the speeds of the SG1 with LSP are higher than the speeds with SG2. The response of buses voltages is better when the LSP system connected. In figure 17, the SG2 and LSP injects the reactive power into the system to regulate the terminal voltage during a three-phase fault [23].

The terminal voltage with LSP case rises up significantly after the fault clearing. Also, the active powers of SG1 in both cases decrease due to voltage drop. After the fault clearing, the active power of SG1 with LSP system increased rapidly because the terminal voltage is recovered. The active power of SG1 with SG2 is swing till reach the value of steady state. The transient stability is improved when LSP plant is connected instead of SG2.

\section{CONCLUSION}

In this paper, the transient stability analysis of the test network system based on real data is performed. The dynamic 
International Journal of Engineering Research and Technology. ISSN 0974-3154, Volume 13, Number 5 (2020), pp. 1030-1038

(C) International Research Publication House. https://dx.doi.org/10.37624/IJERT/13.5.2020.1030-1038

model of the generators with exciter, governor and PSS and LSP plant with LVRT capability are used in this test. In the cases that the system load is increasing and various PV penetration levels up to $30 \%$ are considered, the rotor angle and bus voltages are improved. In the cases that the output power of generator (SG2) is gradually reducing and compensate that with LSP system, the rotor angle and speed of generator are improved till $60 \%$ (based on total output power of SG2) of PV penetration where the rotor angle of the generator (SG2) less oscillated, and causes more stability of the system. In the cases that the replacement of conventional generator (SG2) with LSP system, the results of the time domain simulation show that the voltage response of the power grid is improved, also the active power less oscillated with LSP system.

\section{APPENDIX}

TABLE III

SOLAR-PV SYSTEM PARAMETERS

\begin{tabular}{cc}
\hline \hline Parameter & Value \\
\hline Rated Power (kW) & 450 \\
Open-circuit voltage of module at STC (VO_STC) & $43.8 \mathrm{~V}$ \\
Short-circuit current of module at STC (IS_STC) & $4.58 \mathrm{~A}$ \\
MPP voltage of module at STC (VMPP_STC) & $35 \mathrm{~V}$ \\
MPP current of module at STC (IS_STC) & $5 \mathrm{~A}$ \\
Temperature correction factor (voltage) KV & -0.0039 \\
Temperature correction factor (current) KI & 0.0004 \\
Rated power of a module at STC (W) & 175 \\
No. Parallel Connected Modules & 20 \\
No. Series Connected Modules & 140 \\
\hline \hline
\end{tabular}

\section{ACKNOWLEDGMENT}

This project was funded by King Abdulaziz University, Jeddah, Saudi Arabia and King Abdullah City for Atomic and Renewable Energy, Riyadh, Saudi Arabia. Therefore, the authors gratefully acknowledge their technical and financial support.

\section{REFERENCES}

[1] The International Renewable Energy Agency (IRENA). Global Renewable Generation Continues its Strong Growth, New IRENA Capacity Data Shows. 05April2018.[Online].Available: http://www.irena.org/aboutirena

[2] "NREL Report Shows Utility-Scale Solar PV System Cost Fell Nearly 30\% Last Year", Sept. 12, 2017 [Online].Available: https://www.nrel.gov/news/press/2017/nrel-report-utilityscale-solar-pv-system-cost-fell-last-year.html

[3] "Renewable Energy Now Accounts for a Third of Global Power Capacity",02April2019[Online].Available: https://www.irena.org/newsroom/pressreleases/2019/Apr/Re
newable-Energy-Now-Accounts-for-a-Third-of-GlobalPower-Capacity

[4] The U.S. Energy Information Administration (EIA). Saudi Arabia was world's largest petroleum producer and net exporter in 2012 - Today in Energy - U.S. Energy Information Administration (EIA); June 1, 2017.[Online].Available: https://www.eia.gov/todayinenergy/detail.cfm?id=10231

[5] Saudi's vision 2030. Saudi Arabia's Vision 2030; 2016, p. 84. www.vision2030.gov.[Online].Available: http://vision2030.gov.sa/en/node/87

[6] S. Eftekharnejad, V. Vittal, G. T. Heydt, B. Keel, and J. Loehr, "Impact of Increased Penetration of Photovoltaic Generation on Power Systems," IEEE Transaction on Power System., vol. 28, no. 2, pp. 893-901, May 2013

[7] M. D. Baquedano-Aguilar ; D. G. Colomé ; E. Agüero ; M.G. Molina. "Impact of increased penetration of large-scale PV generation on short-term stability of power systems", IEEE 36th Central American and Panama Convention (CONCAPAN XXXVI). Pp. 1-6, 2016

[8] S. S. Refaat ; H. Abu-Rub ; A. P. Sanfilippo ; A. Mohamed. "Impact of grid-tied large-scale photovoltaic system on dynamic voltage stability of electric power grids", IET Renewable Power Generation. Vol. 12, no. 2, pp. 157-164, 2018

[9] A. Kumar K, M. P. Selvan, K. Rajapandiyan., "Grid Stability Analysis for High Penetration Solar Photovoltaics", 1st Int'1 Re Grid Integration Conference India, pp. 13, Sep. 2017

[10] S. RajaMohamed ; P. ArunaJeyanthy ; D. Devaraj. "Study on the impact of under voltage ride through charactertics of larger PV penetrations on the system transient stability", 4th International Conference on Advanced Computing and Communication Systems (ICACCS). Pp. 1-6, 2017

[11] E.A. Feilata, S. Azzamb, A. Al-Salaymehc. "Impact of large $\mathrm{PV}$ and wind power plants on voltage and frequency stability of Jordan's national grid", Sustainable Cities and Society.Vol. 36, Pp. 257-271, Jan. 2018

[12] Kim, S.; Kang, B.; Bae, S.; Park, J. Application of SMES and grid code compliance to wind/photovoltaic generation system. IEEE Trans. Appl. Supercond. 2013, 23, 5000804.

[13] M. Duong, N. Tran, C. Hossain,” The Impact of Photovoltaic Penetration with Real Case: ThuaThienHue-Vietnamese Grid”, International Conference on Robotics, Electrical and Signal Processing Techniques (ICREST), 2019

[14] R.Jayabarathi, R.Sivaramakrishnan, S.Sruthi, M.Raakesh, B.Manoj," Simulation and Implementation of Solar Power Penetration in an IEEE 5 bus System", 5th International Conference on Advanced Computing \& Communication Systems (ICACCS), 2019

[15] DIgSILENT GmbH, DIgSILENT Power Factory Manual. 2019.

[16] Power System Analysis \& Design, J. Duncan glover , thomas j. Overbye, mulukutla s. Sarma ,sixth edition, 2015. 
International Journal of Engineering Research and Technology. ISSN 0974-3154, Volume 13, Number 5 (2020), pp. 1030-1038

(C) International Research Publication House. https://dx.doi.org/10.37624/IJERT/13.5.2020.1030-1038

[17] "Steady State Stability", January 2, 2019. [Online]. Available: https://www.electrical4u.com/steady-statestability/

[18] U. Andreas, T.S. Borsche and G. Andersson, "Impact of Low Rotational Inertia on Power System Stability and Operation," IFAC World Congress 2014, Capetown, South Africa, 2014.

[19] DIgSILENT GmbH, Heinrich-Hertz-Strasse 9, 72810 Gomaringen / Germany. Technical Reference Static Generator, 2010.

[20] Technical Guideline: Generating Plants Connected to the Medium-Voltage Network, Bundesverband der Energie- und Wasserwirtschaft e.V., BDEW, June 2008

[21] E. Munkhchuluun, L. Meegahapola, A. Vahidnia, "Impact on Rotor Angle Stability with High Solar-PV Generation in Power Networks,"Innovative Smart Grid Technologies (ISGT) Europe Conference 2017, Torino, Italy.

[22] U. Andreas, T.S. Borsche and G. Andersson, "Impact of Low Rotational Inertia on Power System Stability and Operation," IFAC World Congress 2014, Capetown, South Africa, 2014.

[23] O. Mrehel, A. Shamek, M. Hamouda3, "Power System Transient Stability Investigation In The Presence Of Photovoltaic Generation", 17th international conference on Sciences and Techniques of Automatic control \& computer engineering 2016, Sousse, Tunisia, December 19-21, 2016. 